\title{
A Case of Acute Interstitial Nephritis After Two Doses of the BNTI62b2 SARS-CoV-2 Vaccine
}

\author{
Filipe S Mira ${ }^{1,2, *}$ \\ Jóni Costa Carvalho $\mathbb{D D}^{3, *}$ \\ Patrícia Amaral de Almeida (D) ${ }^{4}$ \\ Ana Carolina Pimenta $\left.{ }^{\prime}\right)^{\prime}$ \\ lolanda Alen Coutinho ${ }^{3}$ \\ Carolina Figueiredo' \\ Luís Rodrigues (iD) ${ }^{1,2}$ \\ Vítor Sousa ${ }^{2,5}$ \\ Emanuel Ferreira ${ }^{1,2}$ \\ Helena Pinto ${ }^{1,2}$ \\ Luís Escada ${ }^{1,2}$ \\ Ana Galvão ${ }^{1,2}$ \\ Rui Alves ${ }^{1,2}$ \\ 'Nephrology Department, Coimbra \\ University Hospital, Coimbra, Portugal; \\ ${ }^{2}$ Coimbra University Faculty of Medicine, \\ Coimbra, Portugal; ${ }^{3}$ Allergy and Clinical \\ Immunology Department, Coimbra \\ University Hospital, Coimbra, Portugal; \\ ${ }^{4}$ Internal Medicine Department, Figueira \\ da Foz Hospital, Figueira da Foz, Portugal; \\ ${ }^{5}$ Pathological Anatomy Department, \\ Coimbra University Hospital, Coimbra, \\ Portugal
}

*These authors contributed equally to this work
Background: The development of vaccines to prevent COVID-19 breakouts came with highly positive results but some unexpected side effects. Rare side effects have been seen with the BNT162b2 SARS-CoV 2 vaccine.

Case Presentation: We present the case of a 45 -year-old female patient who developed an acute kidney injury needing urgent hemodialysis one week after the second administration of the BNT162b2 SARS-CoV 2 vaccine. She developed a macular rash on her lower limbs and palms as well. A kidney biopsy was performed 10 days after vaccine inoculation, diagnosing acute interstitial nephritis and acute tubular necrosis with cellular casts. The patient was treated with three corticosteroid pulses followed by daily prednisolone. We witnessed clinical improvement 4 days after the initial corticosteroid treatment with progressive recovery of kidney function and hemodialysis withdrawal. After 2 weeks, the patient had recovered her kidney function. Immunophenotyping was performed, diagnosing a hypersensitivity to the vaccine and the polyethylene glycol excipient.

Conclusion: Patients may develop acute reactions to vaccines. In this case, symptoms seem to correlate significantly with its inoculation and, although this case had a favourable outcome, these side effects must be made aware for clinicians and patients.

Keywords: acute kidney injury, acute interstitial nephritis, proteinuria, COVID-19 vaccine

\section{Introduction}

Ever since the beginning of the coronavirus 2019 (COVID-19) pandemic, the desire for a risk-free and effective vaccine that could prevent new waves of the disease has emerged. This was made possible in the last few months with the explosive development of several vaccines, although their side effects remain a concern and some are still unknown. Most vaccines ever produced are innocuous and cause only minor side effects but, in rare cases, they have been the trigger for glomerular diseases and acute kidney injury (AKI). ${ }^{1}$ At this time, 4 vaccines have been approved to prevent COVID-19: BNT162b2, mRNA-1273 (both mRNA vaccines) JNJ-78436735 and ChAdOx1 nCoV-19 vaccine (both viral vector vaccines). Numerous side effects, common to all the SARS-CoV 2 vaccines, have been described but most appear to be short-lasting and have minimal clinical implications, such as fever, muscle pain, chills and pain at the injection site. There have been a few case reports of kidney side effects associated with the development of AKI, proteinuria, and the need for hospitalization after vaccination with the BNT162b2 vaccine, as well as with the ChAdOx1 nCoV-19 vaccine. ${ }^{2-6}$ Although hemodialysis was necessary in some cases, most patients recovered to their baseline serum creatinine value 3 months after the initial inoculation. There have also been
Correspondence: Filipe S Mira Rua Alfredo Lopes Xisto, $n^{\circ} 36$, Coimbra, 3000-020, Portugal

Tel +351 932463036

Email filipemira@netcabo.pt 
two cases reported of de novo vasculitis after mRNA-1273 (Moderna) vaccine, which improved after immunosuppression and plasmapheresis. ${ }^{7}$ A recent case series reported a greater association between mRNA vaccines (BNT162b2 and Moderna) and kidney disease, presenting with mostly minimal change disease and IgA nephropathy. ${ }^{8,9}$ AIN seems to be present in only a minority of cases. We present the case of a patient with AIN that needs hemodialysis, following the administration of the BNT162b2 COVID-19 vaccine and describe the immunological study and the workup to identify the stimulatory excipient.

\section{Case Description}

A 45-year-old Caucasian woman presented to the emergency department with a 1-week persistent feeling of malaise associated with anorexia, nausea, vomiting and a reduction in urine output the day before being admitted to the hospital. These symptoms started 24 hours after the administration of the second dose of the BNT162b2 COVID-19 vaccine. The patient has denied taking any new medication in the past few months. She denied having fever, as well as any cardiorespiratory symptoms.

Her chronic medication consisted of levothyroxine after a total thyroidectomy due to a multinodular goiter. There was no history of hypertension, or kidney disease (previous laboratory results showed a serum creatinine of $0.85 \mathrm{mg} / \mathrm{dL} 4$ months before).

She was a non-smoker and not a regular alcohol drinker. There was no history of taking any homeopathic drugs/herbal teas.

Upon physical examination, the patient was apyretic and her blood pressure was $126 / 78 \mathrm{mmHg}$, with a peripheral oxygen saturation of $98 \%$ at room air. The patient appeared to be euvolemic, without orthostatic hypotension. She referred to her breathing as foul, like a "festering wound" and had a papular rash on her lower limbs, distributed mostly on her knees, thighs, and palms without pruritus.

Initial blood tests (Table 1) revealed normocytic normochromic anemia, with normal platelets. There was a severe increase in serum creatinine level $(18.4 \mathrm{mg} / \mathrm{dL}$, normal range: $0.5-0.9 \mathrm{mg} / \mathrm{dL}$ ) with hyperkalemia and elevated erythrocyte sedimentation rate $(58 \mathrm{~mm} / 1 \mathrm{~h})$. Her chest X-ray was normal, and her kidney ultrasound described enlarged kidneys (both with 14-15 cm) with no apparent structural abnormalities. Her arterial blood gas analysis showed metabolic acidosis $(\mathrm{pH} 7.157$ and
Table I Initial Laboratory Results

\begin{tabular}{|l|l|l|}
\hline \multicolumn{2}{|l|}{ Blood Tests on Arrival } & Normal Values \\
\hline Hemoglobin $(\mathrm{g} / \mathrm{dL})$ & 10.1 & $12.5-17.5$ \\
\hline Leukocytes $\left(10^{9} / \mathrm{L}\right)$ & 8.5 & $4.0-10.0$ \\
\hline Platelets $\left(10^{3} / \mathrm{L}\right)$ & 391 & $150-400$ \\
\hline Serum creatinine $(\mathrm{mg} / \mathrm{dL})$ & 18.4 & $0.5-0.9$ \\
\hline Serum sodium $(\mathrm{mmol} / \mathrm{L})$ & 134 & $136-145$ \\
\hline Serum potassium $(\mathrm{mmol} / \mathrm{L})$ & 5.7 & $3.5-5.1$ \\
\hline Lactate dehydrogenase $(\mathrm{U} / \mathrm{L})$ & 410 & $125-220$ \\
\hline C reactive protein $(\mathrm{mg} / \mathrm{dL})$ & 1.8 & $0-0.5$ \\
\hline Serum albumin $(\mathrm{g} / \mathrm{dL})$ & 3.1 & $3.5-4.5$ \\
\hline
\end{tabular}

HCO3 $7.6 \mathrm{mmol} / \mathrm{L}$ ) with normal lactate and an anion gap of 16 .

Considering these results, the patient was transferred to a central hospital to start hemodialysis. A central venous catheter was placed, and treatment underwent without complications. A full immune evaluation was performed upon admission to the Nephrology ward (Table 2),

Table 2 Full Immune Evaluation and Specific Tests

\begin{tabular}{|c|c|}
\hline \multicolumn{2}{|c|}{ Additional Blood and Urine Tests Performed } \\
\hline Protein electrophoresis & Normal \\
\hline Immunofixation & Normal \\
\hline $\begin{array}{l}\text { Ratio of kappa and } \\
\text { lambda light chains }\end{array}$ & $1.7 \mathrm{mg} / \mathrm{L}(\mathrm{N}=0.37-3.1 \mathrm{mg} / \mathrm{L})$ \\
\hline C3 & $0.89 \mathrm{~g} / \mathrm{L}(\mathrm{N}=0.83-1.93 \mathrm{~g} / \mathrm{L})$ \\
\hline $\mathrm{C4}$ & $0.3 \mathrm{~g} / \mathrm{L}(\mathrm{N}=0.15-0.57 \mathrm{~g} / \mathrm{L})$ \\
\hline Antinuclear antibodies & Negative \\
\hline Anti-dsDNA & I.7IU/mL $(\mathrm{N}<101 \mathrm{U} / \mathrm{mL})$ \\
\hline $\begin{array}{l}\text { Anti C and P ANCA } \\
\text { antibodies }\end{array}$ & Negative \\
\hline Cryoglobulins & Negative \\
\hline $\begin{array}{l}\text { Hepatitis B, C and HIV } \\
\text { screening }\end{array}$ & Negative \\
\hline $\begin{array}{l}24 \text { hour urine } \\
\text { collection proteinuria }\end{array}$ & $531 \mathrm{mg}$ \\
\hline Urinalysis & $\begin{array}{l}\text { Protein } 100 \mathrm{mg} / \mathrm{dL} \text {; Hemoglobin } 0.2 \mathrm{mg} / \mathrm{dL} \text {; } \\
\text { Leukocytes } 500 \mathrm{cel} / \mathrm{uL} \text { with both leukocytes } \\
\text { and erythrocytes on the sediment }\end{array}$ \\
\hline
\end{tabular}




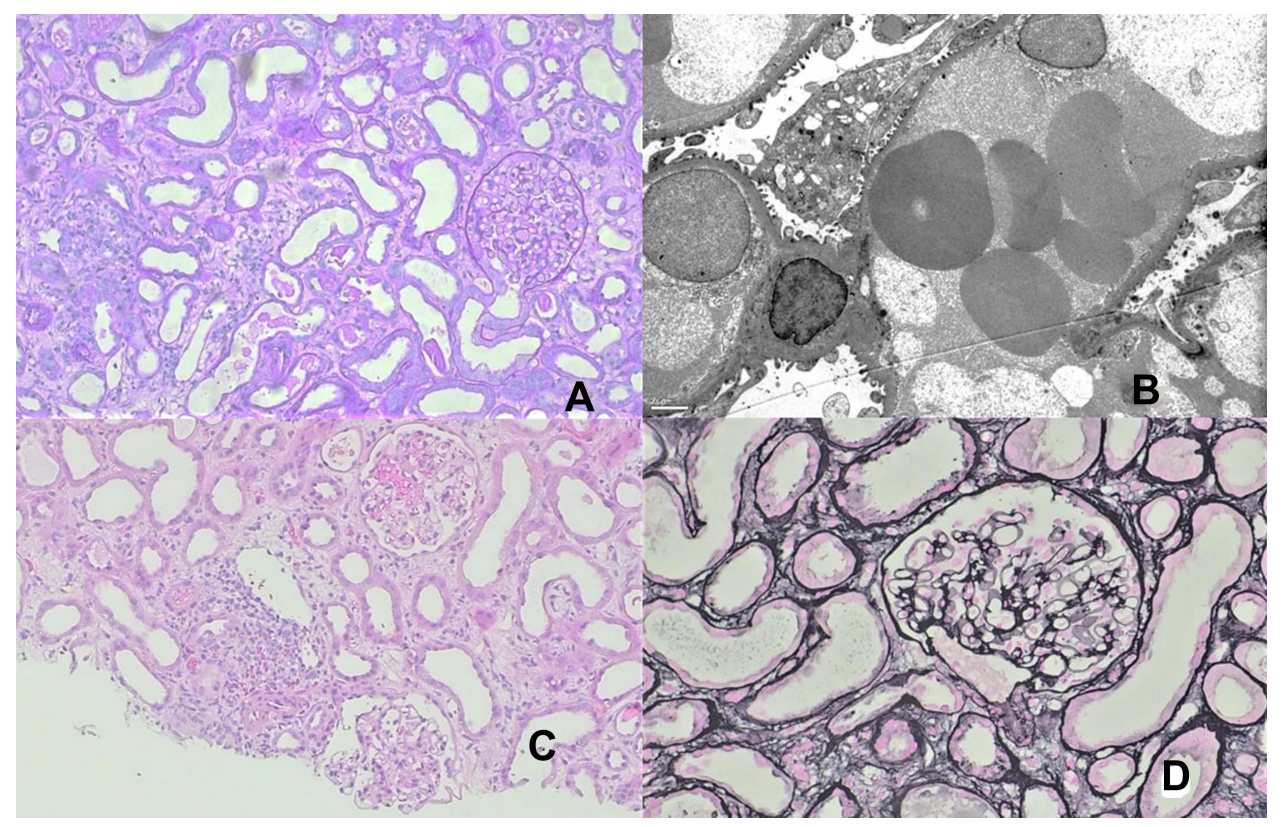

Figure I Kidney biopsy findings. (A) the glomerular compartment is unremarkable: normal capillary wall and no mesangial or endocapillary hypercellularity, renal cortex with inflammation ((A) periodic acid-Schiff stain, original magnification, 200x; (B) electron microscopy exhibiting podocyte focal foot process effacement without changes to the glomerular basement membrane; $(\mathbf{C})$ renal cortex exhibiting mild interstitial edema and inflammation as well as acute tubular injury. (H\&E stain, original magnification, 100x); (D) normal capillary walls without mesangial or endocapillary hypercellularity (Jones methenamine silver stain, original magnification, 200x).

including anti-nuclear antibodies (ANA), antineutrophil cytoplasmic antibodies (ANCA), protein electrophoresis, as well as C3 and C4 serum levels, and every value was normal. Urinalysis showed both red blood cells and white blood cells in the urine as well as proteinuria. Proteinuria on a 24-hour urine collection was $531 \mathrm{mg} / 24 \mathrm{~h}$.

The patient maintained a low urinary output for the first three days, so a kidney biopsy was performed (10 days after the symptoms began).

The glomerulus appeared slightly congestive but with an unremarkable basement membrane and no mesangial or endocapillary hypercellularity. The tubulointerstitial compartment showed findings of mild AIN, edema, and acute tubular necrosis (ATN). The interstitial infiltrate was mainly mononuclear, but focal areas of eosinophilic cells were also observed. Interstitial fibrosis and tubular atrophy (IFTA) were estimated to involve $20 \%$ of the renal cortex (Figure 1A, C and D). Immunofluorescence was negative for IgM, IgG, IgA, C3 and both Kappa and Lambda light chains. Electron microscopy showed non-significant focal podocyte foot process effacement with otherwise unremarkable findings (Figure 1B).

Methylprednisolone was started on three daily $500 \mathrm{mg}$ pulses, followed by $50 \mathrm{mg}$ of prednisolone $(1 \mathrm{mg} / \mathrm{kg})$. Her urinary output increased progressively 5 days after treatment. Central venous catheter was removed at that point.
The cutaneous rash regressed on the second day after corticotherapy.

Blood tests upon discharge (15 days after admission) showed a decreasing serum creatinine of $4.4 \mathrm{mg} / \mathrm{dL}$, with a normal ion pattern and a hemoglobin of $10.7 \mathrm{~g} / \mathrm{dL}$. Protein-to-creatinine ratio in the spot urine sample was $193 \mathrm{mg} / \mathrm{g}$.

The patient returned for follow-up 4 days later and was clinically well. Laboratory tests showed no anemia and a serum creatinine of $1.9 \mathrm{mg} / \mathrm{dL}$. Two weeks later, her kidney function had already normalized $(1.02 \mathrm{mg} / \mathrm{dL})$ with a proteinuria of $33 \mathrm{mg} / \mathrm{g}$. Kidney ultrasound was repeated, revealing normal-sized kidneys without any structural abnormalities.

She remains on a trimonthly nephrology follow-up with progressive corticosteroid wean.

The patient was evaluated at the Allergy and Clinical Immunology Department 2 months after discharge. A drug-induced hypersensitivity reaction (HSR) was considered, and epicutaneous tests, Basophil Activation Test (BAT) and Lymphocyte Transformation Test (LTT) were performed. Epicutaneous tests included the BNT162b2 SARS-CoV-2 vaccine solution with $10 \%$ and $30 \%$ dilution with saline, polyethylene glycol (PEG) 1500 solution (100 mg/mL) polysorbate 20 and 80 at $5 \%$ petrolatum concentration. ${ }^{10}$ Readings were carried out at $48 \mathrm{~h}, 72 \mathrm{~h}$, 
and $96 \mathrm{~h}$, with negative results for all tested allergens. The BAT and LTT were conducted with the vaccine solution and PEG $1500(100 \mathrm{mg} / \mathrm{mL})$. The methodology and concentrations (4 fivefold dilutions) were performed according to the existing literature. ${ }^{11-13}$ Results were considered positive if the stimulation index was higher than 2 for two different concentrations. The BAT result was negative, while the LTT was positive for vaccine solution and PEG 1500 .

\section{Discussion}

AKI related to vaccination has previously been correlated with the influenza vaccine. ${ }^{1}$ Regarding the COVID-19 vaccines, there have been cases of AKI associated with proteinuria, especially with the BNT162b2 COVID-19 Vaccine $^{3-5}$ In some of these cases, hemodialysis was performed due to oliguric AKI and fluid overload, but every case reports a recovery of kidney function at least 3 months after the initial inoculation. In our case, the patient showed initial proteinuria and an AKI with primarily ATN and AIN. The association between the vaccine and AKI can be based on the temporal relationship and LTT results since symptoms appeared approximately 24 hours after its administration with AKI developing one week later. The patient entered complete remission of the disease a few days after starting corticosteroids, which is compatible with previous case reports where corticosteroids were also used successfully. ${ }^{4,5}$

The BAT quantifies in vitro basophil degranulation after drug-specific stimulation. Basophils are implicated in IgE and other mechanisms of immediate-type HSR. ${ }^{11}$ In clinical practice, hypersensitivity categories can overlap, especially when mixed mechanisms are involved, so a BAT was performed even if the clinical history suggested a delayed reaction. ${ }^{11}$ The negative result indicated the unlikely implication of IgE mediated mechanisms.

The LTT determines in vitro whether a patient has developed a drug-specific T-cell response against a particular substance. The significant activation and proliferation of T-cells after direct drug binding indicates a positive result and therefore a possible sensitization to the drug. ${ }^{12,13}$ The LTT is a useful diagnostic procedure for various types of drug-induced hypersensitivity, including AIN. ${ }^{14-17}$ In our case, theoretically, any compound of the vaccine could have elicited an HSR. Excipients are usually the cause rather than the active component. ${ }^{18}$ The PEG 2000 is pointed to as the main allergenic component of the BNT162b2 SARS-CoV-2 vaccine, and, for that reason, the
LTT was performed with vaccine solution and with the excipient PEG 1500 (PEG with an approximate molecular weight since PEG 2000 was unavailable for tests at our center). ${ }^{18}$ The positive results in LTT for both PEG and vaccine solution support T-cell involvement, particularly for PEG specific T-cells, thus pointing to a type IV hypersensitivity reaction, according to the Gell and Coombs classification. $^{18,19}$ Koenig et al categorized the AEFI (adverse events following immunization) according to immune responses, and our case might be included in the "classical adaptive immune-mediated diseases" (mainly involving B- and T-cells and primary lymphoid organs) or "innate immune-mediated diseases" (affecting cells of the innate immune system) categories. ${ }^{28}$

Various potential immunopathogenic mechanisms have been proposed for the involvement of T-cells.

The hypothesis of a delayed HSR associated with antigenic mechanisms (such as the direct binding or conjugation of the vaccine components with host proteins to antigen-specific lymphocytes) is concordant both with the timing of the symptoms and with the test results seen in our case. A drug-induced AIN-like reaction appears to have been the most likely cause of the patient's symptoms.

We could speculate a T-cell mediated injury as part of an aberrant innate and consequent acquired immune response. ${ }^{20-23}$ The mRNA expressing the SARS-CoV-2 spike protein and PEG as immunogenic agents can be themselves triggers to HS-like reactions. ${ }^{21,24}$ An exaggerated reactogenicity may give rise to a cascade of immunological events, eventually leading to the aberrant activation of the immune system, resulting in activation of proinflammatory cascades and immunologic pathways that may play a role in the development of AKI as part of a systemic reaction. ${ }^{20,21,24}$

On the other hand, we might consider, although remote, an immune disease relapse following mRNA vaccine, as described in several reports, including minimal change in disease and membranous nephropathy. ${ }^{25-27}$ However, our patient had no history of kidney disease.

Such a severe AKI leading to the need for hemodialysis may be justified not only by the degree of AIN but also by the existing ATN present in the kidney biopsy. In addition, the presence of proteinuria could be justified by tubular proteinuria present in both ATN and AIN. In our patient, there is also a finding of $20 \%$ IFTA, which may function as a confounding factor that could relate to a previously unidentified kidney disease. Since full immune evaluation was normal and the patient's kidney 
size and function recovered, there was no need for further diagnostic tests.

This case raises awareness of a potentially serious side effect of the BNT162b2 COVID-19 vaccine previously reported, differentiated by the need for hemodialysis due to kidney failure. ${ }^{4}$ There was a complete remission with a full recovery of kidney function after treatment with corticosteroids without relapse after progressive weaning of the drug.

Besides, this is the only study to our knowledge that correlates this systemic symptomatic presentation with T-cell increase in immunophenotyping, not only with the vaccine itself but also with the PEG.

This case brings to light some questions: If the patient is to be vaccinated with a third dose, should we advise her to request a different vaccine? Is she at any risk of developing a similar reaction to the same vaccine or to others that could elicit comparable side effects (such as the influenza vaccine)?

Since there is very little information about this topic and considering the chance of a reproducible HSR after revaccination, as in any drug-induced AIN, it is advised to avoid the culprit drug. Therefore, selecting a COVID-19 vaccine with distinct mechanism and excipient is advised.

As more similar cases are reported, symptoms described in our clinical case seem to correlate with BNT162b2 COVID-19 vaccine inoculation and may represent a significant side effect that must be made aware of for clinicians and patients.

\section{Abbreviations}

AIN, Acute Interstitial Nephritis; AKI, acute kidney injury; ATN, Acute tubular necrosis; ANA, anti-nuclear antibodies; ANCA, antineutrophil cytoplasmic antibodies; BAT, Basophil Activation Test; HSR, hypersensitivity reaction; IFTA, Interstitial fibrosis and tubular atrophy; LTT, Lymphocyte Transformation Test; PEG, Polyethylene glycol.

\section{Ethics Approval and Consent to Participate}

Ethics committee approval was waived.

\section{Consent for Publication}

Written consent to publish this information was obtained from study participants.

\section{Funding}

There is no funding to report.

\section{Disclosure}

Filipe S Mira and Jóni Costa Carvalho are co-first authors of this study. The authors declare that they have no competing interests.

\section{References}

1. Patel C, Shah HH. Vaccine-associated kidney diseases: a narrative review of the literature. Saudi J Kidney Dis Transpl. 2019;30 (5):1002-1009. PMID: 31696837. doi:10.4103/1319-2442.270254

2. Mancianti N, Guarnieri A, Tripodi S, Salvo DP, Garosi G. Minimal change disease following vaccination for SARS-CoV-2. J Nephrol. 2021;34:1-2. doi:10.1007/s40620-021-01091-1

3. Komaba H, Wada T, Fukagawa M. Relapse of minimal change disease following the Pfizer-BioNTech COVID-19 vaccine. Am J Kidney Dis. 2021;78(3):469-470. doi:10.1053/j.ajkd.2021.05. 006

4. Lebedev L, Sapojnikov M, Wechsler A, et al. Minimal change disease following the Pfizer-BioNTech COVID-19 vaccine. Am J Kidney Dis. 2021;78(1):142-145. doi:10.1053/j.ajkd.2021.03.010

5. Weijers J, Alvarez C, Hermans MMH. Post-vaccinal minimal change disease. Kidney Int. 2021;100(2):459-461. doi:10.1016/j.kint.2021. 06.004

6. Leclerc S, Royal V, Lamarche C, Laurin LP. Minimal change disease with severe acute kidney injury following the Oxford-AstraZeneca COVID-19 vaccine: a case report. Am J Kidney Dis. 2021;78(4):607-610. PMID: 34242687; PMCID: PMC8260495. doi:10.1053/j.ajkd.2021.06.008

7. Anderegg MA, Liu M, Saganas C, et al. De novo vasculitis after mRNA-1273 (Moderna) vaccination. Kidney Int. 2021;100(2): 474-476. doi:10.1016/j.kint.2021.05.016

8. Bomback AS, Kudose S, D'Agati VD. De Novo and relapsing glomerular diseases after COVID-19 vaccination: what do we know so far? Am J Kidney Dis. 2021;78(4):477-480. doi:10.1053/j. ajkd.2021.06.004

9. Klomjit N, Alexander MP, Fervenza FC, et al. COVID-19 vaccination and glomerulonephritis. Kidney Int Rep. 2021. PMID: 34632166; PMCID: PMC8493782. doi:10.1016/j.ekir.2021.09.008

10. Johansen JD, Aalto-Korte K, Agner T, et al. European society of contact dermatitis guideline for diagnostic patch testing - recommendations on best practice. Contact Dermatitis. 2015;73(4):195-221. doi:10.1111/cod.12432

11. Ebo DG, Bridts CH, Mertens CH, Sabato V. Principles, potential, and limitations of ex vivo basophil activation by flow cytometry in allergology: a narrative review. J Allergy Clin Immunol. 2021;147 (4):1143-1153. doi:10.1016/j.jaci.2020.10.027

12. Kano Y, Hirahara K, Mitsuyama Y, Takahashi R, Shiohara T. Utility of the lymphocyte transformation test in the diagnosis of drug sensitivity: dependence on its timing and the type of drug eruption. Allergy. 2007;62 (12):1439-1444. doi:10.1111/j.1398-9995.2007.01553.x

13. Pichler WJ, Tilch J. The lymphocyte transformation test in the diagnosis of drug hypersensitivity. Allergy. 2004;59(8):809-820. doi:10.1111/j.13989995.2004.00547.x

14. Kawamata M, Akimoto T, Sugase T, et al. Tubulointerstitial nephritis and uveitis syndrome: are drugs offenders or bystanders? Clin Med Insights Case Rep. 2016;9:21-24. doi:10.4137/CCRep.S36862

15. Fujii T, Kawasoe K, Nishizawa Y, et al. A suspected case of drug-induced tubulointerstitial nephritis by pilocarpine hydrochloride. CEN Case Rep. 2019;8:246-251. doi:10.1007/ s13730-019-00401-8 
16. Koda R, Watanabe H, Tsuchida M, et al. Immune checkpoint inhibitor (nivolumab)-associated kidney injury and the importance of recognizing concomitant medications known to cause acute tubulointerstitial nephritis: a case report. BMC Nephrol. 2018;19(48). doi:10.1186/s12882-018-0848-y

17. Shima H, Okamoto T, Tashiro M, et al. Alogliptin-induced minimal change nephrotic syndrome and interstitial nephritis. Kidney Med. 2019;1(2):75-78. doi:10.1016/j.xkme.2019.03.001

18. Watad A, De Marco G, Mahajna H, et al. Immune-mediated disease flares or new-onset disease in 27 subjects following mRNA/DNA SARS-CoV-2 vaccination. Vaccines. 2021;9(5):435. doi:10.3390/ vaccines 9050435

19. Rajan TV. The Gell-Coombs classification of hypersensitivity reactions: a re-interpretation. Trends Immunol. 2003;24(7):376-379. doi:10.1016/s1471-4906(03)00142-x

20. Segal Y, Shoenfeld Y. Vaccine-induced autoimmunity: the role of molecular mimicry and immune crossreaction. Cell Mol Immunol. 2018;15(6):586-594. doi:10.1038/cmi.2017.151

21. Caso F, Costa L, Ruscitti P, et al. Could Sars-coronavirus-2 trigger autoimmune and/or autoinflammatory mechanisms in genetically predisposed subjects? Autoimmun Rev. 2020;19:102524. doi:10.1016/j. autrev.2020.102524

22. Sette A, Crotty S. Adaptive immunity to SARS-CoV-2 and COVID-19. Cell. 2021;184(4):861-880. doi:10.1016/j.cell.2021.01.007
23. Kalimuddin S, Tham CYL, Qui M, et al. Early T cell and binding antibody responses are associated with COVID-19 RNA vaccine efficacy onset. Med. 2021;2(6):682-688.e4. doi:10.1016/j.medj.2021. 04.003

24. Carvalho JC, Cunha F, Coutinho IA, Loureiro C, Faría E, Todo Bom A. Hypersensitivity reactions to vaccines: current evidence and standards for SARS-CoV-2 vaccines. Acta Med Port. 2021;34 (7-8):541. doi:10.20344/amp.16096

25. Aydın MF, Yıldız A, Oruç A, et al. Relapse of primary membranous nephropathy after inactivated SARS-CoV-2 virus vaccination. Kidney Int. 2021;100:464-465. doi:10.1016/j.kint.2021.05.001

26. Masset C, Kervella D, Kandel-Aznar C, Fantou A, Blancho G, Hamidou M. Relapse of IgG4-related nephritis following mRNA COVID-19 vaccine. Kidney Int. 2021;100(2):465-466. doi:10.1016/ j.kint.2021.06.002

27. Kervella D, Jacquemont L, Chapelet-Debout A, et al. Minimal change disease relapse following SARS-CoV2 mRNA vaccine. Kidney Int. 2021;100:457-458. doi:10.1016/j.kint.2021.04.033

28. Koenig HC, Sutherland A, Izurieta HS, McGonagle D. Application of the immunological disease continuum to study autoimmune and other inflammatory events after vaccination. Vaccine. 2011;29:(5)913-919. doi:10.1016/j.vaccine.2010.10.044
The International Journal of Nephrology and Renovascular Disease is an international, peer-reviewed open-access journal focusing on the pathophysiology of the kidney and vascular supply. Epidemiology, screening, diagnosis, and treatment interventions are covered as well as basic science, biochemical and immunological studies. The manuscript management system is completely online and includes a very quick and fair peer-review system, which is all easy to use. Visit http://www.dovepress.com/testimonials.php to read real quotes from published authors. 